Accepted refereed manuscript of: Cruickshank S \& Barber M (2019) Breast cancer follow-up after a primary diagnosis: A confused picture. Breast, 46, pp. 97-100. DOI: https://doi.org/10.1016/j.breast.2019.05.010

(C) 2019, Elsevier. Licensed under the Creative Commons AttributionNonCommercial-NoDerivatives 4.0 International

http://creativecommons.org/licenses/by-nc-nd/4.0/ 


\section{Breast cancer follow-up after a primary diagnosis: a confused picture}

\section{Abstract}

The follow-up care of people diagnosed with early breast cancer varies across the world. In the UK, services have evolved in an ad hoc way, with no standardized approach nationally. Some people are seen face to face at regular intervals, others are discharged at two years, while others are followed up over the telephone. This is creating confusion for patients as to what is best practice. The lack of evidence to support intensive surveillance is frequently cited as the main reason to reduce or indeed review the benefits of face to face clinical consultations in the hospital/community setting. In addition, a lack of specific recommendations in current guidelines compounds this. Although primary disease stage and treatment are strong indicators of survival, and time to recurrence (both local and distant) is extending, patterns of follow-up care in the UK differ depending on where you live. Yet, European and American guidelines, where survival is frequently reported as being better than the UK, continue to recommend follow-up at regular intervals as part of their overall management approach; to ensure new and changing ways of treating early breast cancer are initiated, managed and monitored accordingly. Indeed their guidelines are increasing rather than decreasing follow-up. While their health systems may differ, survival outcome reporting is not adjusted to reflect these differences.

This paper provides an overview of breast cancer follow-up guidance across the world and opens up a debate about whether patterns of follow up care will affect survival outcomes into the future.

Keywords Breast Cancer, follow-up, aftercare, guidelines, recommendations, best practice

\section{Introduction}

Survival is a key metric of overall progress in cancer control [1] and female breast cancer survival is better than most cancers, with $78 \%$ predicted to survive their disease for ten years or more [2]. It is estimated [3] that there 550,000-570,000 women alive in the UK who have had a diagnosis of cancer. were approximately 200,286 women still alive in the UK 5 years after a breast cancer diagnosis. This figure is set to increase further as use of endocrine therapies are extended or switched between groups of drugs up to 10 years [4] and treatment for recurrent advanced disease becomes more targeted.

Improving overall survival through treatment to reduce the risk of the breast cancer recurring still remains the main goal of treatment but increasingly clinicians have to balance risk of the cancer recurring and risk of persistent and debilitating toxicities [5]. Risks associated with the cancer 
recurring are often difficult to quantify, or indeed explain as; "a risk is something that might happen in the future" [6, p.1] and predicting risk in breast cancer is not an exact science. Research on patterns and risks associated with recurrence are beginning to characterise this risk by breast cancer subtypes such as oestrogen receptor (ER), progesterone receptor (PR), HER2/ErbB2 receptor (HER2), the absence or all three or triple negative breast cancer (TNBC). ER negative breast cancers are associated with a higher risk of recurrence during the initial five years but the risk of recurrence risk increases in ER positive for the next 10 years, and at 15 years the risk equals across the subtypes [7]. This risk unfortunately can continue For those with breast cancer, recurrences peak in the first 2-3 years after diagnosis (10-15\%) [7], but remain a constant risk between $3-5$ years $(4.3 \%)$, and $5-9$ years $(4.6 \%)$ [8] up to and beyond 20 years $[8,9]$.

Detecting early local recurrences or contralateral breast cancer, evaluating and treating therapyrelated complications, motivating patients to continue hormonal treatments and providing psychological support and information in order to enable a return to normal life, whatever the new normal is, is consistently reported as the main purpose of follow-up care [10]. However, some would argue this is "aftercare" an essential part of patient care after treatment of cancer where the primary goal is to reduce disease burden by extending and improving quality of life [11]. The interchangeable use of the terms "follow-up" and "aftercare" is a source of confusion. While aftercare suggests a clear delineation at which treatment ends and this care begins, provided primarily during a period of recovery [12]. Follow-up is a more systematic approach whereby there is a continuation or observation of an individual aftercare is provided through contact between the patient and his/her treating clinicians in relation to the treated cancer. jo

The treatment of breast cancer is more complex than ever. Combining surgery + /- reconstruction, radiotherapy, chemotherapy, endocrine therapy or biological agents are common [13], and in most other areas of medicine, each would be eligible for follow-up in their own right. Commonly the aftercare of one treatment used in breast cancer overlaps with the active treatment of another, and physical and psychosocial problems are not isolated events after any one treatment but occur from the moment breast cancer is suspected, through treatment and beyond. Determining the beginning and end of follow-up is therefore difficult and may reflect the reason why follow up practices have become so variable across the UK.

Previous guidelines in the UK included substantial guidance about how follow-up care should be provided [14. 15, 16], but updated versions have been rather vague $[17,18]$, leading to ambiguity about what is recommended practice, and therefore deemed best practice. While this may reflect a positive trend in overall survival, it has also left patients with breast cancer receiving very different follow-up care, depending on the hospital or region where they live across the UK. Although NICE 
is widely respected, and often cited when difficult decisions in health and social care must be made, their guidance on follow-up is open to wide interpretation.

\section{Review of breast cancer guidelines}

The author reviewed breast cancer guidelines from across the world to understand how each country recommends follow-up surveillance. Guidelines for the management of early breast cancer were sourced from the following organisations: The National Institute for Clinical Excellence (UK) [18], Scottish Intercollegiate Guidelines Network (SIGN)[17], Cancer Care Ontario (CMA) [19], and National Comprehensive Cancer Network (NCCN, USA) [20, 21], Comprehensive Cancer Centre the Netherlands (DF)[22]; European Society of Medical Oncology (ESMO) [10]; Australian National Breast and Cancer Centre (NHMRC) [23] and The Association of Breast Surgery (UK) [24].

\section{Results}

Table 1 shows the fifteen recommendations identified for action within the guidelines. By mapping against these, the author has established a picture of the range of guidance provided by different organisations across the world (Table 2). The only consensus globally is the continuation of mammography. However, while the majority recommend annual mammography, BASO [24], based on research by Kaas et al [25] and Kokko et al. [26] concludes that this could be either annual or bi-annual up to 10 years. These different conclusion based on the same evidence is unhelpful.

Four organisations recommendation switching and/or extending endocrine therapy [10. 18, 20, 24]. However in most cases this is not linked to any detail about appointments, and/or whose responsibility it is to enable it to happen. It is unusual for treatments to be changed or altered in other areas of medicine such as happens in asthma, cardiac, diabetic or respiratory conditions without a follow-up review built in to assess for efficacy, toxicity or adherence. However, it seems that patients with breast cancer don't receive the same service when changes are made. Although some may argue that being less prescriptive is more patient centred, assumptions are being made that after a short consultation, woman and men fully understand the details of their new medication, possible toxicities, benefits and reporting.

In a review of survival data by McCowan et al.[27], those with low adherence to tamoxifen had a shorter time to recurrence, increased medical costs and worse quality of life. In addition, a review of endocrine therapies by Palmieri et al [4] concluded that the extension of endocrine therapies beyond 5 years, including switching between groups of drugs up to 10 years will have implications 
for managing long-term adverse events. There is no standard for how people affected by breast cancer can expect these changes to be implemented into their follow-up care

\section{Discussion}

This guideline review highlighted marked differences between the follow-up recommendations provided in the UK by SIGN [17] and NICE [18] and the more recent guidance provided by Europe [10] and the USA [20,21]. While accepting that the quality of data is sometimes weak in this area, it is still concerning that the recommendations in the UK appear so lacking in any detail. This is particularly so in light of new data published by Allemani et al. [1] who suggest survival outcomes in the UK still lag behind many parts of the world. While some would argue, follow-up surveillance is all about detecting recurrence, evidence suggests that compliance with treatments to extend survival [27] is improved when engagement continues through face to face consultations.

In practice, the arguments for and against the continuation of follow-up surveillance are robustly argued on both sides, and personal preference appears to be driving the decisions within the same networks and regions across the UK. Can it be right that in one area patients are seen regularly and in another region they are discharged at 2 years - where is the evidence for this approach? The introduction of the recovery package [29] , a holistic approach to improve overall co-ordination and management to help people recover, and live well with cancer within the UK, should not be viewed as a substitute for follow-up, or aftercare when treatment changes, rather it should be viewed as complementary.

The $13^{\text {th }}$ St Gallen International Breast Cancer Conference expert panel [30], a highly regarded expert body in collating and disseminating up to date evidence about breast cancer believes that the provision of regular follow-up surveillance at the completion of primary treatment is appropriate and should continue. They support nurse specialists undertaking this care, but recommend it continues to be done in person rather than over the telephone. While telephone follow-up may be an excellent approach to provide psychological support, it cannot confirm or deny local or distant recurrence and this should be made clear to patients.

In conclusion, many of the advances gained about how best to treat breast cancer was as a direct result of data gathering through follow-up surveillance. Breast cancer is entering some uncharted territory with the widespread use of biological agents, patients receiving several lines of treatment and endocrine agents being switched. There are new risks; unknown short and long term side effects and some complicated decisions to be made by patients and their families. If follow-up 
practices continue to be variable, and not necessarily based on any model such as risk stratification, patients may miss out on the optimal treatment approach to extend survival benefit..

There is no conflict of interest.

\section{References}

1. Allemani C et al. and the CONCORD Working Group (2018). Global surveillance of trends in cancer survival 2000-14 (CONCORD-3): analysis of individual records for 37513025 patients diagnosed with one of 18 cancers from 322 population-based registries in 71 countries 391 (10125): 1023-1075 https://doi.org/10.1016/S0140-6736(17)33326-3

2. Cancer Research UK http://www.cancerresearchuk.org/health-professional/cancerstatistics/statistics-by-cancer-type/breast-cancer [accessed June 2018]

3. Ferlay J, Soerjomataram I, Ervik M, Dikshit R, Eser S, Mathers C, Rebelo M, Parkin DM, Forman D, Bray, F. GLOBOCAN 2012 v1.1, Cancer Incidence and Mortality Worldwide: IARC CancerBase No. 11 [Internet]. Lyon, France: International Agency for Research on Cancer. March 2014. Available from: http://globocan.iarc.fr, accessed on 16/01/2015.

4. Palmieri, C., Patten, D, K., Januszewski, A., Zucchini, G., Howell, S.J., 2014. Breast cancer: current and future endocrine therapies. Mollecular and Cellular Endocrinology, 381 (1) pp.695-723

5. Need reference

6. Watson, E.K., Rose, P.W., Neal, R.D., Hubert-Williams, N., Donnelly, P., Hubbard, G., Elliott, J., Campbell, C., Weller, D. \& Wilkinson, C., 2012. Personalised cancer follow-up: risk stratification, needs assessment or both? British journal of cancer, 106 (9) pp.1-5.

7. Ahmed, Aamir., 2013. Pathways to breast cancer recurrence. ISRN Oncology, 2013 pp. 1-16 http://dx.doi.org/10.1155/2013/290568

8. Dixon, J.M. \& Montgomery, D., 2008. Follow-up after breast cancer. British medical journal, 19 (336) pp.107-108.

9. Pan H. Gray R, Braybrooke J, Davies C, Taylor C, McGale P, Peto R, Pritchard KL, Bergh J, Dowsett M, Hayes DF for the EBCTCG* (2017) 20-Year Risks of Breast-Cancer Recurrence after Stopping Endocrine Therapy at 5 Years The New England Journal of Medicine 377: 1836-1846. 
10. Senkus E, Kyriakides S, Ohno S, Penault-Llorca F, Poortmans P, Rutgers E, Zackrisson S, Cardoso F, on behalf of the ESMO Guidelines Committee. Primary breast cancer: ESMO Clinical Practice Guidelines for diagnosis, treatment and follow-up. Annals of Oncology. 2015; 26 (Supplement 5): v8-v30. doi:10.1093/annonc/mdv298.

11. National Borstkanker Overleg Nederland (2012) Breast Cancer Dutch guideline, ver 2.0. http://www.oncoline.nl/breastcancer

12. Medical dictionary https://medical-dictionary.thefreedictionary.com/aftercare [Accessed June 2018]

13. Curigliano $\mathrm{G}$ et al. on behalf of the panel members of the St Gallen International Expert Consensus on the Primary therapy of early breast cancer (2017) De-escalating and escalating treatments for early-stage breast cancer: the St. Gallen International Expert Consensus Conference on the Primary Therapy of Early Breast Cancer 2017. Annals of Oncology, 28 (8): 1700-1712, https://doi.org/10.1093/annonc/mdx308

14. National Institute for Clinical Excellence (NICE), Guidance on cancer services - improving outcomes in breast cancer, http://www.nice.org.uk/pdf/Improving_outcomes_breastcancer_manual.pdf, 2004 [accessed 25.04.2016].

15. National Institute for Clinical Excellence (NICE), Early and locally advanced breast cancer: diagnosis and treatment (NICE Guideline: CG80), http://www.nice.org.uk/CG80, 2009 [25.04.16].

16. Scottish Intercollegiate Guideline Network, Management of breast cancer in women: a national guideline. (Guideline 84) 2005.

17. Scottish Intercollegiate Guideline Network, Management of primary breast cancer. Edinburgh: SIGN [SIGN Guideline: 134] 2013, http://www.sign.ac.uk/pdf/SIGN134.pdf [25.04.16].

18. National Institute of Clinical Excellence (2018) Early and locally advanced breast cancer: diagnosis and management https://www.nice.org.uk/guidance/ng101

19. Saskatchewan Cancer Agency, Cancer (2012) Breast Cancer treatment guidelines https://www.partnershipagainstcancer.ca/db-sage/sage20131524/

20. National Comprehensive Cancer Network (NCCN), Practice guidelines in oncology (NCCN Guidelines Breast Cancer v1). http://www.nccn.org/ 2016 [25.04.2016].

21. National Comprehensive Cancer Network (NCCN), Practice guidelines in oncology (NCCN Guidelines Survivorship v.1). http://www.nccn.org/ 2016 [25.04.2016].

22. National Borstkanker Overleg Nederland (2012) Breast Cancer Dutch guideline, ver 2.0. http://www.oncoline.nl/breastcancer

23. Cancer Australia, Clinical practice guidelines for management of early breast cancer: recommendations for follow-up of women with early breast cancer. 2010. Accessed from http://guidelines.canceraustralia.gov.au/guidelines/early_breast_cancer/ch01.php\#Ch1053Se2284 54 on 25th April 2016. 
24. Surgical Guidelines for the management of breast cancer, Association of Breast Surgery at BASO 2009, Eur J Surg Oncol. 2009; S1-S22. DOI:10.1016/J.EJSO.2009.01.008

25. Kaas R, Hart A A, Besnard A P, Peters J L and Rutgers E J .Impact of mammographic interval onstage and survival after the diagnosis of contralateral breast cancer. BrJSurg.2001;88(1):123-7.

26. Kokko R,Hakama M andHolli K.Follow-up cost of breast cancer patients with localized disease after primary treatment: Arandomized trial. Breast Cancer Res Treat. 2005;93(3):255-60.

27. McCowan, C., Wang, S., Thompson, A, M., Makubate, B., Petrie, D, J., 2013. The value of high adherence to Tamoxifen in women with breast cancer: a community based cohort study. British Journal of Cancer, 109 pp.1172-1180.

28. Jönsson B, Hofmarcher T, Lindgren P, Moen F \& Wilking N. Comparator report on patient access to cancer medicines in Europe revisited - A UK perspective. IHE Report 2017:1, IHE: Lund, Sweden

29. Macmillan Cancer Support (2018) The Recovery package https://www.macmillan.org.uk/aboutus/health-professionals/programmes-and-services/recovery-package

30. Goldhirsch, A., Winer, E.P., Coates, A.S., Gelber, R.D., Piccart-Gebhart, M., Thurliman, B., Senn, H. \& Panel Members, 2013. Personalising the treatment of women with early breast cancer: highlights of the St Gallen international expert consensus on the primary therapy of early breast cancer. Annals of oncology 2013; 24 (9):2206-2013. 